\title{
Por dentro da mobilização global dos motoristas de transporte particular por aplicativo

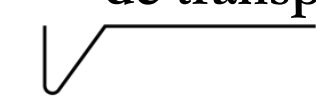

\begin{abstract}
Felipe Moda ${ }^{1}$
Marco Gonsales ${ }^{2}$

\section{Resumo}

No dia 8 de maio de 2019, motoristas que trabalham nas principais empresas de transporte particular por aplicativo realizaram um movimento paredista global por melhores condições de trabalho. Fizemos uma pesquisa na manifestação que ocorreu na cidade de São Paulo, realizando entrevista com os trabalhadores, trabalhadoras, sindicalistas e lideranças do movimento presentes, com o objetivo de conhecer as suas reivindicações e, através delas, aprofundar o debate sobre as condições de trabalho ofertadas pelas empresas de transporte particular por aplicativo e, não obstante, atentarmo-nos para as estratégias e dificuldades de articulação e organização dessa fração da classe trabalhadora, sendo este artigo uma apresentação dos resultados destas entrevistas. A partir dos dados levantados, concluímos que não há uma relação de parceria entre as empresas e os motoristas, sendo estabelecida uma relação capital versus trabalho, com intensa exploração da força de trabalho. A greve global, e tantas outras que eclodem no setor, evidenciam e legitimam a antagônica e conflituosa relação entre motoristas e empresas-aplicativo, com as novas tecnologias da informação e comunicação proporcionando um salto de qualidade na capacidade de controle da empresa sobre os trabalhadores e, ao mesmo tempo, colaborando para novas formas de organização de ações coletivas.
\end{abstract}

Palavras-chave: Greve; Trabalho por aplicativo; Uberização; Uber.

\section{Abstract}

On May 8, 2019, drivers working at major private transportation companies by app realized a global paredist movement for better working conditions. We did a research in the manifestation that took place in the city of São Paulo, carrying out an interview with the workers, unionists and leaders of the movement present, with the aim of getting to know their demands and, through them, deepening the debate on the working conditions offered by private transport companies by app and, nevertheless, pay attention to the strategies and difficulties of articulation and organization of this fraction of the working class, being this article a presentation of the results of these interviews. From the data collected, we conclude that there is no partnership relationship between companies and drivers, in which a capital versus labour relationship is established, with intense exploitation of the workforce. The global strike, and so many others that erupt in the sector, highlight and legitimize the antagonistic and conflicting relationship between drivers and companies-app, being that the new information and communication technologies provide a quality leap in the company's capacity of control over the workers and, at the same time, collaborating for new forms of organization of collective actions.

Keywords: Strike; Work by app; Uberization; Uber.

\footnotetext{
${ }^{1}$ Mestrando do PPGCS da Universidade Federal de São Paulo (Unifesp - Campus Guarulhos), Guarulhos, SP, Brasil; E-mail: felipe.bruner@gmail.com

2 Pós-doutorando em sociologia pelo IFCH-Unicamp. Bacharel, mestre e doutor em Administração de empresas pela PUC-SP; E-mail: professormarcogonsales@gmail.com
} 


\section{Introdução}

No dia 8 de maio de 2019, motoristas "parceiros"3 que trabalham nas principais empresas de transporte particular por aplicativo (Uber, Cabify, 99 e Lyft) realizaram um movimento paredista global por melhores condições de trabalho. O presente artigo é a apresentação da pesquisa que realizamos na manifestação que ocorreu na cidade de São Paulo (Brasil), na qual entrevistamos, com um roteiro semi-estruturado, 18 motoristas presentes. A conformação da amostra foi realizada de maneira não probabilística, com os entrevistados sendo acessados a partir da bola de neve (VINUTO, 2014, p. 203-206), uma técnica que utiliza cadeias de referência, ou seja, um indivíduo entrevistado indica outros possíveis sujeitos para a pesquisa. Para guiarmos as nossas análises, partimos das seguintes questões centrais: Sob quais condições o trabalho de motorista por aplicativo é desempenhado? Quais eram as principais reivindicações dos presentes na manifestação e como eles se organizaram para realizar o protesto? Desta forma, o nosso objetivo com o presente artigo é compreender como a contradição capital versus trabalho se materializa no trabalho por aplicativo.

A data escolhida pelos trabalhadores e trabalhadoras para a realização do protesto foi um dia antes de a maior empresa do setor, a Uber, estrear os seus papéis na bolsa de valores estadunidense. As manifestações aconteceram principalmente em cidades estadunidenses como Boston, Washington, Nova York e Los Angeles, mas ocorreu também em cidades de outros países, como Sydney, Melbourne e Brisbane (Austrália), São Paulo (Brasil), Montevidéu (Uruguai), Londres (Inglaterra), Santiago (Chile), San José (Costa Rica), Nairóbi (Quênia) e Lagos (Nigéria), entre outras.

Nos Estados Unidos da América, a paralisação em Nova York durou duas horas, das 7 às 9, com os motoristas exigindo um dólar por milha e vinte centavos por minuto em tarifas, bem como horas extras e benefícios, sendo que em São Francisco, os motoristas realizaram protesto na sede da Uber e desligaram os seus aplicativos por 12 horas (GREVATT, 2019). Em Londres, apoiados pelo sindicato Independent Workers Union, os protestos também se concentraram na sede da Uber, com os trabalhadores desligando os

\footnotetext{
${ }^{3}$ A palavra "parceiro" é utilizada entre aspas por ser o termo utilizado pelas empresas para se referirem aos motoristas.
} 
seus aplicativos entre 7 e 16 horas e exigindo melhores pagamentos por corrida, ampliação do seguro de vida e condições mais favoráveis para o financiamento de veículos (HOROWITZ, 2019). Na Austrália, os trabalhadores reivindicaram melhores remunerações, direito para negociar o contrato de trabalho, redução da comissão das empresas, seguro de renda mínima e um tribunal independente para lidar com conflitos entre usuários e motoristas (THE CANBERRA TIMES, 2019).

Em São Paulo, os motoristas começaram a se concentrar às 8 horas no Vale do Anhangabaú, região central da cidade, e, por volta das 10 horas, cerca de 200 pessoas foram em marcha até a sede da Bolsa de Valores de São Paulo. Após retornarem ao local de concentração, os motoristas saíram em carreata até o Museu de Arte de São Paulo, travando importantes avenidas da região central da cidade.

Para elucidar a nossa reflexão sobre as condições de trabalho ofertadas pelas empresas de transporte particular por aplicativo (TPA) e como as formas de resistência à plataformização ${ }^{4}$ do trabalho estão sendo gestadas, dividimos este artigo em três seções: (1) O transporte particular por aplicativo (2) As condições de trabalho e o gerenciamento do trabalho pelo assalariamento camuflado; e, por fim, (3) A greve global dos motoristas: reivindicações e formas de articulação.

\section{O transporte particular por aplicativo}

Os aplicativos de mediação de transporte surgiram em 2010, com a criação da empresa Uber por Garret Camp e Travis Kalanick. Em seus 10 anos de existência, a empresa teve forte expansão, passando a operar em mais de 10 mil cidades em todo o mundo e contando com mais de 5 milhões de motoristas e 111 milhões de usuários cadastrados em sua plataforma (UBER, 2020). Outra gigante do setor é a empresa chinesa Didi Chuxing, que recentemente adquiriu a brasileira 99. Com forte presença no continente asiático, a Didi é responsável por marcas como a Ola, na Índia, a própria Uber, na China, além de ter participação na estadunidense Lyft, e efetua em média 30 milhões de corridas por dia. Também importante empresa do setor é a Cabify, integrante da holding espanhola

\footnotetext{
4 Utilizamos os termos aplicativos e plataformas como sinônimos. As plataformas são infraestruturas de softwares e hardwares, de propriedade privada ou pública, alimentadas por dados, automatizadas e organizadas por meio de algoritmos digitais (CASILLI, POSADA, 2019).
} 
Maxi Mobility e que iniciou as suas atividades em 2011, em Madri. Atualmente opera em mais de 90 cidades e, no início de 2019, integrou a empresa Easy, consolidando-se como a terceira maior operadora no mercado brasileiro.

No Brasil, a primeira empresa a oferecer esse tipo de serviço também foi a Uber, começando a funcionar em maio de 2014, no Rio de Janeiro, sendo que em 2019 já prestava serviço em mais de 100 cidades. Na cidade de São Paulo, a Uber iniciou os seus trabalhos em junho de 2014, e em 2018 já contava com cerca de 150 mil motoristas cadastrados na empresa ou em aplicativos que oferecem serviços similares, número superior ao de taxistas, que são cerca de 50 mil, sendo esta a cidade do mundo que mais realiza corridas utilizando o aplicativo (LEWER, 2018).

Resumidamente, o serviço funciona da seguinte maneira: um consumidor cadastrado na plataforma da empresa solicita, via aplicativo, uma corrida informando o local de origem e de destino. A chamada para a corrida aparece no display do celular de um dos motoristas, com ele tendo alguns segundos para aceitar ou recusar o pedido e, caso aceite, um mapa de GPS ajuda na sua condução até o usuário. Após a realização do encontro entre eles, o aplicativo indica a melhor rota entre o local de origem e de destino, sendo que ao final do translado o sistema calcula o valor da corrida. Encerrada a prestação do serviço, motorista e passageiro avaliam um ao outro a partir um sistema de pontuação de estrelas. Do valor total da corrida, uma parcela da tarifa é retida pela empresa e a outra serve de pagamento ao motorista.

Apesar de essas companhias prestarem serviço de transporte particular, tais empresas se definem como do ramo de tecnologia, tendo como propósito administrarem plataformas digitais que conectam motoristas e passageiros, enquadramento que facilita a adoção de políticas de flexibilidades com os motoristas. Os profissionais são classificados como prestadores terceiros autônomos pelas empresas, o que permite que os direitos trabalhistas previstos pela Consolidação das Leis Trabalhistas (CLT) não sejam garantidos (POCHMANN, 2017). Tampouco as empresas de TPA oferecem uniformes, ferramentas, como o automóvel e o celular, ou materiais para o auxílio da função exercida.

Para tornar-se um "parceiro" dessas empresas, basta instalar o aplicativo de uma delas em seu telefone celular, ter ou locar um carro de um dos modelos requeridos e enviar para a empresa fotos da sua carteira de motorista, do veículo e da certificação de antecedentes criminais, sem nenhum contato direto entre a corporação e o motorista. Após 
esse processo, o trabalhador é cadastrado na plataforma e, a todo o momento em que ligar o aplicativo, passará a receber oportunidades de viagens solicitadas por passageiros. É importante salientarmos que as empresas não realizam processo seletivo para cadastrar trabalhadores em sua plataforma e inexiste um número fixo de pessoas que prestam serviço utilizando os aplicativos por cidade, tornando uma escolha pessoal desses profissionais engajar neste trabalho.

O arranjo tecnológico envolvido nessa forma de trabalho é o surgimento das empresas-aplicativo (ABÍLIO, 2017). Tais empresas se auto intitulam como meras mediadoras entre consumidores e trabalhadores autônomos, tendo como sua responsabilidade apenas prover a infraestrutura necessária para esses trabalhadores executarem os seus serviços e para o encontro deles com uma multidão de consumidores, cobrando uma porcentagem do serviço prestado decorrente desse encontro (ABÍLIO, 2017; SLEE, 2017, p. 26). Porém, em nossa opinião, estamos nos deparando com formas camufladas de contratação da força de trabalho, já que se estabelece uma relação de hierarquia e de subordinação dos trabalhadores às plataformas (ABÍLIO, 2019; AMORIM; MODA, 2020). Nossa conclusão parte do fato de que ao se conectarem com as plataformas através dos aplicativos, os trabalhadores estão submetidos a uma autoridade externa que gerencia a demanda dos clientes, determina as tarefas a serem realizadas, estabelece unilateralmente o valor de troca do serviço e da força de trabalho, e controla a execução do trabalho e o seu desempenho, além de determinar gratificações ou punições (FONTES, 2016; FRANCO; FERRAZ, 2019; GANDINI, 2018).

A introdução de aplicativos nos diferentes processos de trabalho está promovendo importantes mudanças na forma de gerenciamento, organização e controle da força de trabalho, conformando o que vem sendo chamado de gerenciamento algorítmico (MÖHLMANN \& ZALMANSON, 2017; ROSENBLAT, STARK, 2016). Se no início do século XX vivenciamos a hegemonia taylor-fordista para organizar a produção, período marcado pela adoção de tarefas diárias e individuais, desenvolvidas pela gerência, para cada trabalhador e pela esteira de montagem, responsável por automatizar o controle do tempo disponível para realização de cada tarefa (GOUNET, 2002; GRAMSCI, 2001; TAYLOR, 1990), na década de 1970 vivenciamos o crescimento do chamado toyotismo. A principal inovação da gestão toyotista foi a adoção do fluxo tensionado (ANTUNES, 2009; CORIAT, 1994; DURAND, 2003; GOUNET, 2002; HARVEY, 1992), criando uma 
indústria mais flexível, racional e que evitaria desperdícios, principalmente na constituição de estoques dentro do processo produtivo e de tempo e custo de produção (PREVITALI; FAGIAN, 2014). Estas transformações foram possibilitadas pela introdução das Novas Tecnologias da Informação e Comunicação (NTICs) nos processos de trabalho, possibilitando a "organização pela dispersão" (HARVEY, 1992, p. 150), com as grandes empresas estabelecendo redes de micros e pequenas empresas terceirizadas.

Atualmente, o que temos é a mesma lógica: as empresas-aplicativo, através da apropriação da tecnologia - do saber dos trabalhadores e trabalhadoras -, ampliam a capacidade de organização e controle do trabalho. Porém, passam a se conectar não mais apenas com a sua rede de empresas terceiras, mas também diretamente com os seus trabalhadores, tornando eles próprios terceirizados. O intuito último dessas plataformas é alterar a relação entre trabalho vivo e trabalho morto, restaurando a dominação capitalista (CINGOLANI, 2016, p. 42-43), ou seja, é mais uma forma de incorporar o saber-fazer dos trabalhadores e trabalhadoras às máquinas, visando aumentar o poder de controle do capital sobre o trabalho.

O gerenciamento algorítmico está permitindo um novo salto de qualidade na organização e no controle do trabalho, promovendo uma redução da autonomia do trabalhador, tanto individual quanto coletivo, para realizar suas atividades. No que tange ao trabalhador individual, dados e informações são constantemente objetivados e lhes transmitidos via aplicativo, direcionando-os para as rotas mais curtas na realização dos trajetos, para as vias menos congestionadas e para as regiões com maior número de clientes em potencial, diminuindo assim a possibilidade de tomadas de decisão sobre o seu trabalho.

Porém, as modificações gerenciais implementadas a partir da utilização de aplicativos não afetam apenas a produtividade do trabalhador individual, já que os motoristas não atuam como indivíduos dispersos e isolados, e sim conformando uma força produtiva social, um trabalhador coletivo (ROSDOLSKY, 2001). A gerência algorítmica permite uma maior organização desse trabalhador coletivo, já que a grande capacidade da plataforma em reter e analisar dados faz com que milhões de motoristas ao redor do mundo tenham a organização do seu trabalho realizada de maneira coordenada e em tempo real. Isso possibilita, por exemplo, que com apenas 22 mil funcionários, a Uber gerencie mais de cinco milhões de motoristas ao redor do mundo. 


\section{As condições de trabalho e o gerenciamento do trabalho pelo assalariamento camuflado}

Uma das características centrais do TPA é a não fixação, por parte das empresas, de jornadas e locais de trabalho, dando aos trabalhadores autonomia para decidirem em quais dias trabalharão, quanto tempo permanecerão dirigindo e os locais em que ligarão o aplicativo para receber pedidos. Ao final de cada corrida, é gerado um valor baseado no tempo gasto, na distância percorrida e na relação entre oferta e demanda de motoristas na região, sendo que, desta tarifa, um percentual fica com a empresa e outro com o motorista. Não é realizada mais nenhuma forma de remuneração para esses profissionais, seja por meio de bonificações, seguros ou auxílio em caso de acidentes. Assim sendo, a remuneração mensal desses trabalhadores é totalmente variável, sem nenhuma base fixa, o que impacta diretamente nas suas condições de trabalho.

Essa forma de organização do trabalho está se mostrando bastante eficaz na implementação do autogerenciamento dos trabalhadores sobre o processo de trabalho (ABÍLIO, 2019), já que a jornada de trabalho alcançada está acima das 8 horas diárias, conformando 44 horas semanais, previstas em nossa legislação trabalhista. As jornadas extenuantes são uma prática comum dos motoristas, como relatado em algumas das entrevistas por nós realizadas:

Cara, é loucura, é loucura. Eu me levanto às 3h30 da manhã, 3h45 ligo o carro e $4 \mathrm{~h}$ estou saindo. Paro meio-dia para almoçar, descansar um pouco, e $14 \mathrm{~h}$ volto a trabalhar e vou até às $23 \mathrm{~h}$ ou meia-noite. E isso é todo dia, todo dia, para tirar um trocado no final do dia. Porque gasta 100 reais de combustível, depois você gasta 20 reais de almoço e fazendo corrida de 7 ou 10 reais não tem como virar. Você tem que se matar (ENTREVISTA, 02).

A partir do relato dos próprios trabalhadores, a jornada de trabalho diária média é de 12 horas, muitas vezes 6 dias na semana. As pesquisas desenvolvidas por Kalil (2019), que entrevistou 100 motoristas de TPA em São Paulo, e por Moraes, Oliveira e Accorsi (2019) chegaram a um resultado parecido, com mais do que a metade dos trabalhadores afirmando realizarem jornadas diárias superiores a 10 horas. Além disso, muitos dos entrevistados relataram desenvolver outros trabalhos como forma de complementar os seus ganhos. 
Apesar de as empresas de TPA apresentarem como eixo de propaganda para os motoristas a capacidade de eles terem jornadas mais flexíveis do que os trabalhos regulamentados pela CLT, temos que, na prática, a única flexibilidade existente é a hora pela qual o serviço é prestado, já que a duração total da jornada é, muitas vezes, superior em relação às ocupações formalizadas. A extensão da jornada de trabalho está impactando diretamente a dinâmica social e familiar dos motoristas:

Olha, particularmente eu quero ver um meio rápido de não depender apenas do aplicativo. Está muito complicado. Hoje a minha realidade é que eu moro no meu carro e visito a minha casa. Essa é a minha realidade, moro no carro e visito a minha casa. Meus filhos não devem nem saber mais quem é o pai deles, sabem que de vez em quando eu sou o cara que vai lá deixar um dinheiro (ENTREVISTA 05).

Sobre o valor da remuneração, os motoristas relatam que com uma jornada de trabalho de 10 a 12 horas diárias, seis dias por semana, faturam aproximadamente 6 mil reais. Subtraindo a taxa cobrada pelas empresas-aplicativos, o combustível e pagando o aluguel do carro, em média, sobra 30\% desse valor para os motoristas, aproximadamente 2 salários mínimos. No entanto, os motoristas por aplicativo, como trabalhadores informais, não contam com o recebimento de um piso salarial, décimo terceiro salário, férias remuneradas, depósitos no FGTS, horas extras com o respectivo adicional, repouso semanal remunerado, adicional noturno e hora noturna reduzida, intervalo intra e interjornadas, benefícios convencionais e proteção previdenciária compulsória com contribuição do empregador. Para aqueles que financiam ou utilizam o carro particular, a remuneração costuma ser ainda menor e compreender os gastos como a depreciação e o financiamento do veículo tornase um dilema, como podemos perceber na fala de um dos entrevistados:

A média semanal é de 1.200 reais bruto. Se trabalhar, é isso! [...] Eu calculo que eu perco uns 40\%, para não ficar triste. Vem para uns 700 reais semanais [...]. Eu tenho um gasto com o seguro, que é mais caro, com combustível, que roda muito, com a manutenção no carro, a gente roda muito, e a chance de dar problema mecânico é maior (ENTREVISTA 10).

Outro tema importante que gostaria de ressaltar é sobre o modelo de remuneração adotada pelas empresas de TPA, no gerenciamento do processo de trabalho. Por compreendermos a relação de trabalho estudada como estruturada a partir da subordinação dos motoristas das empresas, defendemos a existência de um assalariamento camuflado da força de trabalho baseado no assalariamento por peça/tarefa (AMORIM; MODA, 2020; 
FRANCO; FERRAZ, 2019; KREIN et al, 2018, p. 106). Como os motoristas recebem uma parcela do pagamento por corrida realizada, podemos fazer um paralelo com a forma de remuneração citada, baseada em um cálculo variável e percentual sobre o que é produzido, em vez de ser um valor fixo repassado periodicamente para o trabalhador, como o salário por tempo de trabalho.

No capítulo XIX do livro "O Capital” (2012), Marx afirma que "[...] o salário por peça não passa de uma forma a que se converte o salário por tempo, do mesmo modo que o salário por tempo é a forma a que se converte o valor ou o preço da força de trabalho" (MARX, 2012, p. 645). Logo, ambas as formas de assalariamento seguem a mesma determinação na composição do seu valor. Porém, a remuneração por peça promove diferenças na forma pela qual o trabalho é executado, por tornar interesse pessoal do trabalhador a intensificação do seu ritmo de trabalho e prolongar a sua jornada (MARX, 2012, p. 648-649).

Dessa forma, o que aparentava ser liberdade, na realidade se apresenta como uma eficiente ferramenta para ampliar e intensificar o ritmo de trabalho. Tal como apontado por Dal Rosso (2017, p. 11-12), o processo de flexibilização das horas trabalhadas não visa a diminuição das jornadas, mas flexibilizar a força de trabalho para aumentar a criação de valor das empresas, já que permite diminuir gastos com capital variável em períodos de menor demanda de trabalho.

Assim, defendemos que estamos diante do aprofundamento da chamada produção just in time toyotista, já que passamos agora para a existência dos trabalhadores just in time (ABÍLIO, 2017; 2019; De Stefano, 2016; Oliveira, 2002, p. 16). Esses trabalhadores são pessoas que estão à disposição para o trabalho 24 horas por dia, embora tal jornada não ocorra concretamente, acabando com a distinção entre tempo de trabalho e tempo de não trabalho, já que todo o tempo existente torna-se, em potencial, tempo de trabalho. Como a remuneração ocorre apenas pelas horas efetivamente trabalhadas, todo intervalo passa a ser visto como possibilidade de aumentar os rendimentos, com os trabalhadores ficando submetidos às flutuações da demanda pelo serviço e permitindo que as empresas invistam em capital variável na quantia exata necessária. 


\section{A greve global dos motoristas: reivindicações e formas de articulação}

Entre aqueles e aquelas que têm o seu trabalho organizado e controlado por intermédio de plataformas digitais, os motoristas das empresas de TPA são pioneiros na construção de ações coletivas para buscar melhorias nas suas condições de trabalho, com grande destaque para protestos ocorridos na Índia. Como exemplo, em de fevereiro de 2017 mais de 100 mil motoristas, em Bangalore e Nova Deli, paralisaram as suas atividades por duas semanas, sendo esta a maior manifestação do setor já registrada em todo o mundo. As reivindicações presentes neste protesto diziam respeito a melhores remunerações, pela possibilidade de serem representados por associações e sindicatos e pela redução do número de profissionais ativos (NAISHADHAM, 2017).

A organização dos trabalhadores das empresas de TPA para a realização de ações coletivas trazem novos desafios, que vão além dos enfrentados historicamente pela classe trabalhadora. Em uma indústria ou em uma grande prestadora de serviço, os empregados trabalham lado a lado e em tempo integral, o que facilita a comunicação e a organização entre eles, e a inexistência desse espaço físico faz com que um dos objetivos de uma greve, o de interromper as atividades da empresa, seja dificultado. Além disso, o enquadramento desses trabalhadores como prestadores de serviços autônomos faz com que a própria existência de vínculo empregatício seja questionada. As dificuldades encontradas para superar esses inúmeros desafios foram percebidas desde o momento em que chegamos na manifestação, às 8 horas, já que a ausência de uma convocatória única para o protesto fez com que diversos horários e locais fossem divulgados, dificultando o início do protesto.

A partir destas dificuldades, o binômio resistência versus cooptação ganha nova roupagem no início do século XXI, com as empresas de transporte por aplicativos aprendendo estratégias que limitem as manifestações e as paralisações. Exemplo desta nova estratégia foi o preço das corridas terem ficado mais cara em São Paulo no dia do protesto, incentivando motoristas a irem trabalhar (LOBEL et al., 2019). A adoção de preços flutuantes e a posse, por parte da empresa, dos dados referentes ao funcionamento da prestação do serviço, permitem que as ações de resistência sejam contrabalanceadas em tempo real, impondo aos trabalhadores a necessidade de buscar novos repertórios em suas ações. 
O fato de os motoristas organizarem a sua jornada de trabalho, de terem os seus ganhos vinculados à produtividade, de trabalharem para diversos empregadores e a ideia de que o empregador e responsável é o cliente, são dificuldades concretas sentidas pelos motoristas para a realização de ações coletivas. Tais características, inerentes ao trabalho do TPA, foram expressas pelos presentes no protesto, com diversos entrevistados verbalizando as ambiguidades existentes na sua relação de trabalho:

Eu acho que é uma opção de trabalho. Ela oferece a plataforma, e a opção sou eu quem tenho, de ir ou não ir. Funcionário da Uber eu não me considero porque a gente vai na hora que quer, não tem obrigação. Ela oferece a plataforma só e é independente. É tipo um autônomo. [...] Não, não. Eu vim inclusive porque a minha classe está sendo explorada demais, eu acredito. Porque a remuneração está baixa, o risco está alto, e a gente precisa fazer alguma coisa para melhorar isso (ENTREVISTA 12).

Soma-se a esses elementos o discurso propagado pela empresa de uma aparente parceria entre a corporação e os trabalhadores. Ao utilizar determinada terminologia, tal como "parceiros" em vez de "trabalhadores", a empresa busca não apenas burlar a legislação trabalhista vigente, mas também construir nos motoristas uma visão de mundo desassociada da existência de uma relação de exploração da força de trabalho, causando a impressão de que seus ganhos dependem apenas dos seus esforços individuais, como se fossem empresários-de-si-mesmo (DARDOT; LAVAL, 2016). Esta visão foi expressa por um dos motoristas entrevistados:

Não, eu trabalho para mim mesmo. Eu faço assim, que hoje em dia o
motorista de aplicativo é dono do próprio negócio dele. É claro que ele
precisa da Uber, dos outros aplicativos, para ter um cliente, porque por
causa de uma regulamentação isso tem que passar por uma plataforma,
não tem jeito. Mas quem são os nossos patrões não são os aplicativos, a
Uber, a 99, a Cabify, são os próprios passageiros. Se você não agradar ele,
se você não der um bom atendimento para ele, você não vai ter mais. Não
adianta ter adesivo, câmara no carro monitorada 24 h, o importante é o
passageiro. Se você não der um bom atendimento para ele, não adianta
nada (ENTREVISTA 03). Como apontado por Lima (2010, p. 188), muitos dos trabalhadores submetidos a vínculos precários de trabalho absorvem a lógica empreendedora como explicativa e justificadora da sua condição, responsabilizando-se por se manter em sua função e se protegendo da condição de vítima. São pessoas que se veem em eterna necessidade de 
aumentar o seu "capital humano", como se eles fossem uma empresa com capacidade de autovalorização constante, mistificando o grau de exploração existente nesta forma de trabalho.

Apesar destas inúmeras dificuldades, havia um amplo consenso entre os presentes sobre as reivindicações da categoria. Os motoristas reclamavam das baixas tarifas cobradas pelas empresas, do congelamento do preço da tarifa, que estava corroendo seus lucros devido ao grande aumento dos preços dos combustíveis, da elevada taxa cobrada pelas empresas por cada corrida e da baixa segurança. Ou seja, as principais reivindicações dizem respeito à remuneração e à falta de segurança para exercer a profissão.

No caso da Uber, a tarifa mínima cobrada pela empresa para uma corrida é menor do que 6 reais. Considerando a gasolina utilizada para chegar até o passageiro e depois para transportá-lo e a taxa média de 25\% cobrada pela empresa, as corridas com taxa mínima tem ganho praticamente nulo. Além disso, faz três anos que o valor da tarifa não é atualizado, sendo que a política de flutuação dos preços de combustíveis aplicada no Brasil desde 2016 está fazendo os ganhos dos motoristas serem menores a cada dia, levando a uma situação desesperadora para muito dos presentes:

O meu amigo me emprestou um dinheiro para dar de entrada no carro, e eu dei 14 mil de entrada e financiei o resto. $\mathrm{Na}$ época que eu entrei, dava para pagar o carro tranquilo, tudo certinho. Mas de um tempo para cá, a gasolina foi aumentando, a inflação também, e daí já não consigo pagar mais nada. [...] Dia 30 de julho já era, acabou para mim porque preciso pagar o IPVA do carro, a documentação. Então já era para mim, se eu ficar com o meu carro na rua, ele vai ser apreendido. Aí eu vou tentar fazer... sei lá, vender água no farol, não sei. Eu não vou perder um bem que dei 14 mil de entrada por besteira e eu também não posso ficar parado (ENTREVISTADO 14).

O tema segurança no trabalho também desperta a atenção da categoria. Para ilustrarmos a gravidade da questão, dados divulgados pela Secretaria de Segurança Pública de São Paulo mostram que em 2017 tivemos 3.952 casos de roubos a motoristas enquanto desempenhavam a sua atividade. No primeiro trimestre de 2018 , esse número já era 18,5\% maior que o mesmo período do ano anterior (ALCOVERDE; PERRONI, 2018). É

\footnotetext{
5 Para a teoria do capital humano, desenvolvida principalmente pelos economistas estadunidenses Theodore Schultz (1973) e Gary Becker (1964), os trabalhadores devem investir continuamente em suas capacidades adquiridas, o que ocorre principalmente a partir da formação educacional, visando aumentar o seu valor no mercado, ou seja, os trabalhadores que se autovalorizarem de maneira mais efetiva teriam maiores chances de aumentarem a sua renda e vencerem socialmente.
} 
importante salientarmos que em grande parte desses casos a ação foi realizada por passageiros utilizando contas fakes cadastradas nas plataformas. Frente a isso, os trabalhadores cobram das plataformas iniciativas que dificultem a criação de contas pelos usuários do serviço, realizando os cadastros com um maior número de dados pessoais.

No que tange às lideranças do movimento, um fenômeno interessante aconteceu na manifestação de São Paulo. Youtubers, sindicalistas e membros de coletivos formados por grupos de WhatsApp disputavam as falas no microfone, novidades ocasionadas pela democratização do acesso a aparelhos celulares no Brasil.

Assim, as mesmas tecnologias que ampliam a capacidade de controle das empresas de TPA, através do fracionamento e da individualização do trabalho, também possibilitam aos trabalhadores novas alternativas para romper com o isolamento característico desse setor e organizar ações coletivas. As principais plataformas de comunicação entre os trabalhadores são os aplicativos de mensagens como WhatsApp e Telegram, e redes sociais como Facebook e YouTube. Tais grupos foram determinante para a convocação do protesto.

Fiquei sabendo pelas redes sociais, WhatsApp principalmente. A gente tem os grupos aí, eu estou em 19 grupos. Então a gente vai se comunicando entre nós mesmos. As primeiras que tiveram foi o nosso grupo, né, que é esse "Tudo nosso", que tem adesivinho em alguns carros, foi a gente que agitou a galera, que começou. Então é mais pelos grupos mesmo, daí depois vem Facebook, Instagram, mas a grande maioria é pelo grupo de WhatsApp (ENTREVISTA 07).

Todos os presentes relataram estar em dezenas de grupos de mensagens instantâneas. Os motoristas desenvolvem amizades, laços de solidariedade e pensam ações coletivas a partir desses grupos. Desta forma, o ambiente digital torna-se assim um espaço público e parece contribuir contra o isolamento dos trabalhadores após o desmantelamento das fábricas fordistas.

Em cada um desses grupos foram articuladas diferentes ações para o dia de protestos, mas a aparente horizontalidade do movimento é desfeita nas entrevistas realizadas. Aceitar ou refutar a atuação das ferramentas tradicionais de organização da classe trabalhadora, tais como os sindicatos, era algo polêmico entre os presentes. Muitos acreditam que essas ferramentas podem contribuir para aumentar o poder de representação da categoria, porém outros entendem que são os próprios motoristas os mais eficientes na luta por melhores condições de trabalho. 
Sinceramente? Eu acredito que não. Porque assim, até tem, existem alguns aí denominados sindicatos que estão aí desde 2016, e até hoje eu não vi nada, não vi nenhuma melhoria, quando a gente quer alguma coisa, a gente mesmo que tem que ir atrás. Eu vejo muito interesse nisso, então, para mim, é motorista por motorista. O mesmo que fizemos hoje vamos fazer outro dia se for necessário, se a Uber não atende à nossa reivindicação, a gente para outro dia, paramos outra data, paramos amanhã, depois de amanhã... Enfim, eu acho que é nós por nós mesmos (ENTREVISTA 07).

De todo modo, entre os que defendem ou que são contra a existência de um sindicado da categoria, existe um jargão consensual imposto pelos motoristas para as lideranças: "A pessoa tem que correr com nós". "Correr com nós" foi uma expressão bastante repetida pelos motoristas, não indicando uma defesa da ausência de lideranças, mas um embrião de crítica à burocracia do movimento sindical tradicional.

\section{Considerações finais}

As empresas de TPA afirmam estabelecer uma relação de parceria com os motoristas. No entanto, as evidências apontam a existência de uma subordinação típica da relação capital versus trabalho. Essa relação só é possível pois o principal meio de produção utilizado para o gerenciamento da força de trabalho, a própria plataforma, é de propriedade particular, tornando os trabalhadores dependentes da empresa para realizarem suas atividades (FRANCO, FERRAZ, 2019).

As empresas de TPA se beneficiam da utilização dos aplicativos para gerenciar a força de trabalho, pois os cálculos algorítmicos que orquestram o seu funcionamento permitem avançar na capacidade de organizar e controlar o trabalho. Além disso, as longas e intensas jornadas de trabalho narradas pelos trabalhadores demonstram como as empresas-aplicativo, ao mesmo tempo, racionalizam os seus processos produtivos, aumentando a extração da mais-valia em sua forma relativa, se valem também da ampliação da jornada de trabalho, extraindo a mais-valia absoluta.

Desta forma, temos, mais uma vez, como resultado dos avanços tecnológico o aumento da subsunção real dos trabalhadores ao capital (MARX, s/d). As NTICs foram cruciais para a desomogeneização do operário-massa fordista (BIHR, 2010, p. 83-104) e para o desmantelamento do movimento operário vinculado ao pacto fordista, visto como um dos principais entraves para a implementação do toyotismo (GOUNET, 2002). A 
acumulação flexível, ou toyotismo, baseou-se na utilização das NTICs, conectadas à internet e com funcionamento em rede, para desmembrar cadeias produtivas e fragmentar a classe trabalhadora em diferentes formas de contrato, tornando o trabalho mais individualizado e diminuindo o poder reivindicatório dos sindicatos (HARVEY, 1992). Agora, as empresas-aplicativo se utilizam de novas tecnologias para individualizar ainda mais o trabalho e aumentar a sua capacidade de controle e coordenação do trabalhador coletivo a elas subordinados.

Porém, algumas décadas após a utilização das NTICs para desorganizar a classe trabalhadora, elas passam também a cumprir o papel importante de aproximação dos trabalhadores, em especial devido à democratização do acesso aos aparelhos celulares e das redes sociais. Isso não significa dizer que o trabalho está menos individualizado e fragmentado, já que as empresas-aplicativo levam ao extremo essa fragmentação ao considerar os seus trabalhadores como autônomos e remunerá-los com salários completamente individualizados. Mas, ao permitirem o aumento do contato entre esses profissionais, a tecnologia está também contribuindo para a construção de tradições, opiniões e visões comuns entre os trabalhadores, formando uma consciência partilhada sobre as condições de trabalho as quais estão inseridos.

Para além de conectar os trabalhadores, as NTICs estão contribuindo, como já dito, para a criação de novas lideranças das categorias. O funcionamento em rede dessas ferramentas permite que novos atores compitam com a função dos sindicatos na organização dos protestos, sendo esta uma característica que está se generalizando na contemporaneidade. O papel do celular e das redes sociais na organização de ações coletivas foi marcante na Primavera Árabe de 2011 (BORGES, 2012), na greve dos caminheiros no Brasil de 2018 (BBC, 2019) e nos protestos antigoverno de Hong Kong de 2019 (RFI, 2019), por exemplo, configurando-se assim como um componente central para compreendermos as formas de articulação da classe trabalhadora contemporânea.

Assim, trabalhadores e trabalhadoras buscam reinventar as suas formas de organização para a realização de ações coletivas. Após décadas de ataques às suas estruturas organizativas, com parte delas sendo realizadas por meio da adoção de tecnologias de comunicação por parte das empresas nos processos de trabalho, na contemporaneidade parte da classe trabalhadora busca assimilar as tecnologias disponíveis para repensar as suas ações. Ainda é cedo para medirmos a efetividade destas novas formas organizativas para 
garantir melhores condições de trabalho, bem como avaliar o impacto destas medidas para transformar as formas históricas de representação da classe trabalhadora, como os sindicatos. Porém, colocarmos luz sobre estas práticas é fundamental para compreendermos a luta de classes nos dias atuais.

\section{Referências}

ABÍLIO, L. Uberização do trabalho: subsunção real da viração. Passa Palavra, 19 fev. 2017. Disponível em: http:/ / passapalavra.info/2017/02/1106 85. Acesso em: 11 jun. 2019.

$\begin{array}{lcr}\text { ABÍLIO, L. } & \text { Uberização: do } \\ \text { empreendedorismo } & \text { para } & \text { o } \\ \text { autogerenciamento } & \text { subordinado. }\end{array}$ Psicoperspectivas, v. 18, n. 3, 2019.

ALCOVERDE, L; PERRONI, A. Roubos a motoristas de aplicativos crescem 18,5\% em São Paulo. G1, 16 maio 2018. Disponível em: https://g1.globo.com/sp/saopaulo/noticia/roubos-a-motoristas-deaplicativos-crescem-185-em-saopaulo.ghtml. Acesso em: 28 maio 2019.

AMORIM, H.; MODA, F. B.. Trabalho por aplicativo: gerenciamento algorítmico e condições de trabalho dos motoristas da Uber. Fronteiras - estudos midiáticos, v. 22, n. 1, 2020.

ANTUNES, R. Os sentidos do trabalho: ensaio sobre a afirmação e a negação do trabalho. São Paulo: Boitempo, 2009. 287 p.

BBC. Como o WhatsApp mobilizou caminhoneiros, driblou o governo e pode impactar eleições. G1, 2 jun. 2019.

\section{Disponível}

em: https://g1.globo.com/economia/tecnol ogia/noticia/como-o-whatsappmobilizou-caminhoneiros-driblougoverno-e-pode-impactar-eleicoes.ghtml. Acesso em: 6 out. 2019.

BECKER, G.. Human capital: a theoretical and empirical analysis, with special reference to education. New York: National Bureau of Economic Research, 1964. 402p.

BIHR, A. Da grande noite à alternativa: o movimento operário europeu em crise. São Paulo: Boitempo, 2010. 284p.

BORGES, T. Redes sociais foram combustíveis para revolução no mundo árabe. Opera Mundi, 4 jan. 2012. Disponível em: https://operamundi.uol.com.br/politicae-economia/18943/redes-sociais-foramo-combustivel-para-as-revolucoes-nomundo-arabe. Acesso em: 16 ago. 2019.

CASILLI, A.; POSADA, D. The platformization of labor and society. In: GRAHAM, M.; DUTTON, W. (org.). Society and the Internet. Oxford: OUP, 2019. p. 293-306.

CINGOLANI, P. Capitalismo de plataforma: nuevas tecnologías de la 
comunicación e internacionalización del trabajo. Boletín Onteaiken, n. 22, 2016. p. 42-47.

CORIAT, B. Pensar pelo avesso. Rio de Janeiro: Editora Revan, 1994. 212p.

DAL ROSSO, S. O ardil da flexibilidade: os trabalhadores e a teoria do valor. São Paulo: Boitempo, 2017. 286p.

DARDOT, P.; LAVAL, C.. A nova razão do mundo: ensaio sobre a sociedade neoliberal. São Paulo: Boitempo, 2016. 411p.

DE STEFANO, V.. The Rise of the 'Justin-Time Workforce': On-Demand Work, Crowd Work and Labour Protection in the 'Gig-Economy'. Bocconi Legal Studies Research Paper, 2015. 35p.

DURAND, P. J. A refundação do trabalho no fluxo tensionado. Tempo Social, Departamento de Sociologia da USP, São Paulo, v. 15, n. 1, 2003. p. 139158.

FRANCO, D. S.; FERRAZ, D. L. S. Uberização do trabalho e acumulação capitalista. Cad. EBAPE.BR, v. 17, Edição Especial, Rio de Janeiro, Nov. 2019. p. 844-856.

FONTES, V. Capitalismo em tempos de uberização: do emprego ao trabalho. In: COLÓQUIO MARX E MARXISMO 2016: CAPITAL E PODER, 10., 2017, Niterói-RJ. Anais. Niterói-RJ, 2016. p. 4567.

GANDINI, Alessandro. Labour process theory and the gig economy. Human Relations, 2018. p. 1-18.
GOUNET, T. Fordismo e toyotismo na civilização do automóvel. São Paulo: Boitempo, 2002. 120p.

GRAMSCI, A. Americanismo e fordismo. In: GRAMSCI, A. (org.). Cadernos do Cárcere. Rio de Janeiro: Civilização Brasileira, 2001. v. 4. 396p.

GREVATT, M. Uber stock sales flop as global rideshare workers strike! Workers World, 14 maio 2019. Disponível em: https://www.workers.org/2019/05/423 05. Acesso em: 10 out. 2019.

HARVEY, D. Condição pós-moderna: uma pesquisa sobre as origens da mudança cultural. São Paulo: Edições Loyola, 1992. 349p.

HOROWITZ, J. Uber drivers go on strike to protest low pay ahead of a blockbuster. CNN, 2019. Disponível em: https://edition.cnn.com/2019/05/08/te ch/uber-strike/index.html. Acesso em: 13 out. 2019.

KALIL, R. B. Capitalismo de plataforma e direito do trabalho: crowdwork e trabalho sob demanda por meio de aplicativos. 2019. Tese (Doutorado em Direito) Faculdade de Direito, Universidade de São Paulo, São Paulo, 2019. 373p.

KREIN, J. D et al. Flexibilização das relações trabalhistas: insegurança para os trabalhadores. In: KREIN, J. D.; GIMENEZ, D. M.; SANTOS, A. L. Dimensões críticas da reforma trabalbista no Brasil. Campinas: Curt Nimuendajú, 2018. p. 95-123.

LEWER, L. SP é a cidade que usa Uber no mundo; aplicativo é citado por $52 \%$ dos entrevistados. Folha de S. Paulo, 29 abr. 2018. Disponível em: https://www1.folha.uol.com.br/o- 
melhor-de-sao-

paulo/servicos/2018/04/1966515-sp-ea-cidade-que-mais-usa-uber-no-mundoaplicativo-e-citado-por-52-dosentrevistados.shtml. Acesso em: 30 jul. 2019.

LIMA, J. C. Participação, empreendedorismo e autogestão: uma nova cultura do trabalho?. Revista Sociologias, Porto Alegre, ano 12, n. 25, 2010. p. 158-198.

LOBEL, F.; OLIVEIRA, F.; DALL'AGNOL, L.; PAMPLONA, N. Preços de corrida em SP sobem em dia de paralisação global de motoristas de Uber. Folha de S.Paulo, 8 maio 2019. Disponível em:

https://www1.folha.uol.com.br/mercad o/2019/05/precos-de-corrida-em-spsobem-em-dia-de-paralisacao-global-demotoristas-de-uber.shtml. Acesso em: 11 mai. 2019.

MARX, K. Capitulo VI Inédito de O Capital. São Paulo: Moraes, s/d..

MARX, K. O Capital - Livro 1. Rio de Janeiro: Civilização Brasileira, 2012. 571p.

MORAES, R. B. S.; OLIVEIRA, M. A. G.; ACCORSI, A. Uberização do trabalho: a percepção dos motoristas de transporte particular por aplicativo. Revista Brasileira de Estudos Organizacionais. v. 6, n. 3, p. 647- 681, 2019.

MÖHLMANN, M.; ZALMANSON, L.. Hand on the Wheel: navigating algorithmic management and Uber drivers' autonomy. Anais do International Conference on Information Systems (ICIS 2017). Seul, 2017.

NAISHADHAM, S. More trouble for Uber: 100,000 drivers in India went on strike. Vice, 24 fev. 2017. Disponível em: https://www.vice.com/en_us/article/pg $\mathrm{v} 7 \mathrm{gv} /$ more-trouble-for-uber-10000drivers-in-india-went-on-strike. Acesso em: 13 ago. 2019.

OLIVEIRA, F. Passagem na neblina. In: OLIVEIRA, F.; STEDILE, J. P.; GENOINO, J. (org.). Classes sociais em mudança e a luta pelo socialismo. São Paulo: Fundação Perseu Abramo, 2002. p. 7-22.

PREVITALI, F. S.; FAGIANI, C. C. Organização e controle do trabalho no capitalismo contemporâneo: a relevância de Braverman. Cad. EBAPE.BR, v. 12, no 4, artigo 1, Rio de Janeiro, Out./Dez. 2014. p. 756-769.

POCHMANN, M. A nova classe do setor de serviços e a uberização da força de trabalho. Revista do Brasil, São Paulo, 2017. Disponível em: http://www.redebrasilatual.com.br/revis tas/130/a-nova-classe-do-setor-deservicos-e-a-uberizacao-da-forca-detrabalho. Acesso em: 6 jun. 2019.

RFI. Conheça 10 táticas urbanas usadas nos protestos de Hong Kong. G1, 17 ago. 2019. Disponível em: https://g1.globo.com/mundo/noticia/2 019/08/17/conheca-10-taticas-urbanasusadas-nos-protestos-de-hongkong.ghtml. Acesso em: 6 out. 2019.

ROSDOLSKY, R. Gênese e estrutura de O Capital de Karl Marx. Rio de Janeiro: Eduerj: Contraponto, 2001. 623p.

ROSENBLAT, A.; STARK, L.. Algorithmic Labor and Information Asymmetries: A Case Study of Uber's Drivers. International Journal of Communication, N. 10, 2016. p. 3758-3784. 
SCHULTZ, T.. Capital bumano: investimento em educação e pesquisa. Rio de Janeiro: Zahar, 1973. 250p.

SLEE, T. Uberização: a nova onda do trabalho precarizado. São Paulo: Elefante, 2017. 314p.

TAYLOR, F. Princípios da administração científica. São Paulo: Atlas, 1990. 144p.

THE CANBERRA TIMES. Australia joins global Uber outcry. The Canberra Times. 8 maio 2019. Disponível em: https://www.canberratimes.com.au/stor y/6112240/australia-joins-global-uberoutcry/?cs=14231. Acesso em: 16 out. 2019.

UBER. Fatos e dados sobre a Uber. 2020. Disponível em: https://www.uber.com/pt$\mathrm{BR} /$ newsroom/fatos-e-dados-sobreuber. Acesso em 10 abr. 2020.

VINUTO, J. A amostragem em bola de neve na pesquisa qualitativa: um debate em aberto. Temáticas. Campinas, v. 44, 2014. p. 203-220. 